\title{
Technical Note: Fast two-dimensional GC-MS with thermal extraction for anhydro-sugars in fine aerosols
}

\author{
Y. Ma ${ }^{1, *}$, M. D. Hays ${ }^{1}$, C. D. Geron ${ }^{1}$, J. T. Walker ${ }^{1}$, and M. J. Gatari Gichuru ${ }^{2}$ \\ ${ }^{1}$ National Risk Management Research Laboratory, United States Environmental Protection Agency, Research Triangle Park, \\ North Carolina 27711, USA \\ ${ }^{2}$ Institute of Nuclear Science \& Technology, College of Architecture and Engineering, University of Nairobi, Nairobi, Kenya \\ * currently at: California Air Resources Board, 9528 Telstar Avenue, El Monte, CA 91731, USA
}

Received: 20 November 2009 - Published in Atmos. Chem. Phys. Discuss.: 5 January 2010

Revised: 23 April 2010 - Accepted: 26 April 2010 - Published: 7 May 2010

\begin{abstract}
A fast two-dimensional gas chromatography (GCMS) method that uses heart-cutting and thermal extraction (TE) and requires no chemical derivatization was developed for the determination of anhydro-sugars in fine aerosols. Evaluation of the TE-GC-GC-MS method shows high average relative accuracy $(\geq 90 \%)$, reproducibility $(\leq 10 \%$ relative standard deviation), detection limits of less than $3 \mathrm{ng} / \mu \mathrm{L}$, and negligible carryover for levoglucosan, mannosan, and galactosan markers. TE-GC-GC-MS- and solvent extraction (SE)-GC-MS-measured levoglucosan concentrations correlate across several diverse types of biomass burning aerosols. Because the SE-GC-MS measurements were taken 8 years prior to the TE-GC-GC-MS ones, the stability of levoglucosan is established for quartz filter-collected biomass burning aerosol samples stored at ultra-low temperature $\left(-50^{\circ} \mathrm{C}\right)$. Levoglucosan concentrations $(\mathrm{w} / \mathrm{w})$ in aerosols collected following atmospheric dilution near open fires of varying intensity are similar to those in biomass burning aerosols produced in a laboratory enclosure. An average levoglucosan-mannosan-galactosan ratio of 15:2:1 is observed for these two aerosol sets. TE-GC-GC-MS analysis of atmospheric aerosols from the US and Africa produced levoglucosan concentrations $\left(0.01-1.6 \mu \mathrm{g} / \mathrm{m}^{3}\right)$ well within those reported for aerosols collected globally and examined using different analytical techniques $\left(0.004-7.6 \mu \mathrm{g} / \mathrm{m}^{3}\right)$. Further comparisons among techniques suggest that fast TE-GC-GCMS is among the most sensitive, accurate, and precise methods for compound-specific quantification of anhydro-sugars. In addition, an approximately twofold increase in anhydrosugar determination may be realized when combining TE with fast chromatography.
\end{abstract}

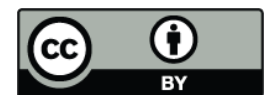

Correspondence to: M. D. Hays (hays.michael@epa.gov)

\section{Introduction}

Levoglucosan (LG, 1,6-anhydro- $\beta$-D-glucopyranose) is an important organic marker for biomass burning. Characterizaion of LG has contributed much to our understanding of the global atmosphere. Biomass fires produce relatively high quantities of LG with minor amounts of other anhydro-sugars or monosaccharide anhydrides (e.g., mannosan - MAN, and galactosan - GAL). These compounds form at fire temperatures greater than $300^{\circ} \mathrm{C}$ as plant cellulose and hemicellulose decomposes and molecular bonds cleave via transglycosylation, fission, and disproportionation reactions (Shafidazeh et al., 1984). LG partitions exclusively to a submicrometer liquid or solid aerosol phase (Kleeman et al., 2008), and is stable in the atmosphere during long-range transport (Fraser et al., 2000). Thus, once formed as a pyrolysis product of biomass combustion, it is used as an organic marker in atmospheric modeling studies (Fraser et al., 2000; Simoneit et al., 1999a, b, 2001; Elias et al., 2001), in sediment and Antarctic ice cores for understanding the paleorecord (Gambaro et al., 2008), in liquid biofuel synthesis (Branca et al., 2003; Gravitis et al., 2004), and as a urinary biomarker for approximating animal and human exposures to biomass smoke (Migliaccio et al., 2009). For these reasons, there is high demand for quantitative analytical data for LG.

The excellent review by Schkolnik and Rudich (2006) summarizes the quantitative analytical methods for LG in atmospheric aerosols. It separates techniques for LG measurement into two general categories: gas chromatography (GC) methods (Simoneit et al., 2001; Zdrahal et al., 2002; Pashynska et al., 2002; Otto et al., 2006) and aqueousphase methods. Aqueous-phase methods are applied less frequently to study LG in aerosols but are emerging due to their speed and lack of a chemical derivatization requirement. For example, Gao et al. (2003) paired IC with electrospray

Published by Copernicus Publications on behalf of the European Geosciences Union. 
ionization (ESI)-ion-trap MS to directly examine LG and carbohydrates in African biomass fire plumes. Others subsequently investigated the anhydro-sugars with LC-MS, developing methods for time-of-flight (TOF) (Dye et al., 2005), quadrupole (q) (Wan et al., 2007) and triple quadrupole (qqq) MS systems (Gambaro et al., 2008). For these studies, LCMS sensitivity for $\mathrm{LG}$ was shown to be $0.014 \mathrm{ng} / \mu \mathrm{L}$ or less (Wan et al., 2007). Additional water-based techniques that have successfully measured LG in aerosols include capillary electrophoresis (CE)-pulsed amperometric detection (PAD) - which measures LG in as little as 2 min (Garcia et al., 2005) - and high-performance anion-exchange chromatography with PAD (HPACE-PAD) which detects LG at concentrations above $0.002 \mathrm{ng} / \mu \mathrm{L}$ (Engling et al., 2006).

Despite the emergence of LC-MS and other aqueous phase techniques, GC-MS techniques are more routinely applied to quantify LG in aerosols (Schkolnik et al., 2006). These GC-MS methods can detect LG as a tri-methyl silyl analogue with nanogram or better sensitivity. However, aerosol sample preparation for GC-MS analysis can require multiple solvent extraction (SE), concentration, and chemical derivatization (i.e., silyation) steps, which are labor-intensive, timedemanding, reagent-consuming and usually environmentally unfriendly (Schkolnik et al., 2006). Moreover, silylated LG is susceptible to hydrolysis, expiring within $24 \mathrm{~h}$ (Wan et al., 2007). Attempts to detect LG on certain GC column stationary phases without chemical derivatization using GC-MS can result in a lower response due to peak spreading (Fraser et al., 2000; Williams et al., 2006; Fine et al., 2001). And while faster, the increased detection limits resulting from this practice may preclude the use of LG as a biomass burning marker in the highly time-resolved atmospheric samples needed for coupling source-receptor models and epidemiological studies (Williams et al., 2006).

Thermal extraction (TE) methods have quantitatively determined organic aerosol composition and are simpler than and as accurate as traditional SE methods for many analyses (Hays et al., 2003; Falkovich et al., 2001; Chow et al., 2007; Lin et al., 2007). They require less sample preparation than SE, minimize parasite peaks caused by solvent and laboratory contamination, and are more sensitive (Chow et al., 2007; Lin et al., 2007). However, the quantification of polar organic compounds has challenged single dimension TE-GC-MS techniques; whereas, two-dimensional GC systems $(\mathrm{GC} \times \mathrm{GC}$ (comprehensive) or GC-GC (heartcutting)) have improved the separation of complex aerosol mixtures (Welthagen et al., 2003; Kallio et al., 2003; Hamilton et al., 2004; Ma et al., 2008). Further, GC $\times$ GC TOFMS has tentatively identified highly polar sugar substituents in biomass samples (Hope et al., 2005). In fact, we recently produced qualitative evidence showing how TE combined with GC-GC-MS sharply resolved polar organic analytes in biomass smoke without chemical derivatization ( $\mathrm{Ma}$ et al., 2008). For the present study, the focus is on the accurate and reproducible quantification of underivatized LG and other anhydro-sugar molecules in biomass burning and atmospheric aerosols using TE-GC-GC-MS. Application of this method to aerosols is verified through proficiency testing and by comparing results for samples also analyzed by SE-GCMS following silyation. In the interest of reducing the long analysis times typically associated with GC-MS, the TE-GCGC-MS method is modified to include fast chromatography via modular accelerated column heating (MACH). The combination of MACH with TE requires less total sample preparation and analysis time than most chromatographic methods available currently. Following method development, anhydro-sugar concentrations for a variety of biomass burning aerosols and atmospheric environments impacted by fires of varying intensity are reported. Finally, we offer evidence that LG in biomass burning aerosol stored at ultra-low temperatures $\left(-50^{\circ} \mathrm{C}\right)$ is stable for nearly a decade.

\section{Experimental}

\subsection{Chemicals}

Authentic anhydro-sugar standards were used without further purification. LG (1,6-anhydro- $\beta$-D-glucopyranose), MAN (1,6-anhydro- $\beta$-D-mannopyranose), GAL (1,6-anhydro- $\beta$ D-galactopyranose) were obtained from Sigma-Aldrich Co. (St. Louis, MO), Advance Scientific \& Chemical Inc. (Fort Lauderdale, FL), and from a source at Colorado State University. Deuterated LG (Cambridge Isotope Laboratories) was used as the internal standard. Methanol (Sigma-Aldrich) was used to dissolve target and internal standard compounds.

\subsection{Aerosol samples}

A total of eight particulate matter (PM) samples collected on pre-fired $\left(550^{\circ} \mathrm{C}, 12 \mathrm{~h}\right)$ quartz fiber filters $(47 \mathrm{~mm}, 67 \mathrm{~mm}$, and hi-vol filters with $432 \mu \mathrm{m}$ thickness Pallflex, Pall Corporation) were selected for examination. Of these, three were collected from biomass burning simulations conducted in an enclosure. Extensive details about the enclosure, sample collection, and fire regimes can be found in Hays et al. (2002, 2005). Briefly, mixed forest floor debris dominated by loblolly pine (Pinus taeda) needles (collected from Duke University Forest, Durham, NC) and post-harvest agricultural crop residue from rice and wheat fields (Sutter County, CA, USA; and Lind, WA, USA respectively) were gathered and burned in the enclosure. The fine aerosol $(<2.5 \mu \mathrm{m}$ mean aerodynamic diameter) emissions were cooled $\left(\sim 25^{\circ} \mathrm{C}\right)$, diluted ( $\sim 1: 50$ ), and collected using a custom-fabricated stainless steel dilution sampler outfitted with sampling arrays that housed the quartz filters being examined here.

Additionally, fine aerosol emissions from two biomass burning events were collected using the $\mathrm{PM}_{2.5}$ cuts from a high-volume dichotomous sampler (MSP Corporation, MN). The first event was a 2006 prescribed fire at Croatan National Forest $\left(\mathrm{CNF}, 35.92^{\circ} \mathrm{N}, 77.07^{\circ} \mathrm{W}\right)$, New Bern, NC, 
USA. Here, the fuel was primarily indigenous shrubs and mixed forest litter dominated by loblolly pine with less than $20 \%$ hardwood in the overstory. The $2.5 \mathrm{~km}^{2}$ fire consumed roughly $200-500 \mathrm{~g}$ of fuel per $\mathrm{m}^{2}$ and took place 2 days after a $20 \mathrm{~mm}$ rainfall. Ignition was under low ventilation, high humidity conditions shortly after fog had lifted. Although the fire was not highly energetic, the flaming stage was well sampled over two $37 \mathrm{~min}$ and $70 \mathrm{~min}$ periods. The second sampling event occurred in September 2007 immediately following a North Carolina-Piedmont region $\left(35.98^{\circ} \mathrm{N}, 79.09^{\circ} \mathrm{W}\right)$ wildfire that had earlier consumed approximately $0.01 \mathrm{~km}^{2}$ (1 ha) of pine litter and mixed hardwood forest biomass. A $14 \mathrm{~h} \mathrm{PM}_{2.5}$ sample (PMT) was collected at night during the low intensity residual smoldering of heavy fuels. (The smoldering was mostly organic soils, stump, and large diameter fuels.) For the most part, sampling took place under low- or intermittent-smoke or smoke-free conditions. A beta gauge indicated a $15-200 \mu \mathrm{g} \mathrm{m}^{-3} \mathrm{PM}_{2.5}$ mass range.

Two PM samples were collected from an urban atmosphere in Nairobi, Kenya influenced by biomass burning. In Kenya, biomass is used for cooking and heating (Kituyi et al., 2001). Industrial and domestic wastes that contain cellulosebased products are also burned for warmth. Two ambient samples (KNY01 and KNY02) were taken in August and October 2006 at an urban field site near the city center of Nairobi, Kenya (University of Nairobi, $1.3^{\circ} \mathrm{S}, 36.8^{\circ} \mathrm{E}$ ). Particles with aerodynamic diameters of approximately $35 \mu \mathrm{m}$ or less were collected using a high volume sampler (MSP) positioned $20 \mathrm{~m}$ above ground. These samples were expected to contain more dust due to the supercoarse diameter cut-off. A third atmospheric aerosol sample (KSV) was collected $(270 \mathrm{~L} / \mathrm{min})$ over roughly $24 \mathrm{~h}$ in November, 2006 at Kenansville, NC, USA. The rural Kenansville site was in close proximity to a number of animal production facilities but was not significantly impacted by biomass fire. Filter samples were stored in pre-fired aluminum foil and stored at $-50^{\circ} \mathrm{C}$ in a low-temperature freezer prior to analysis.

\subsection{TE-GC-GC-MS analysis}

A schematic diagram (Supporting Information, Fig. S1, http://www.atmos-chem-phys.net/10/4331/2010/ acp-10-4331-2010-supplement.pdf) and detailed description of the TE-GC-GC-MS system and extraction procedure used for the present study can be found elsewhere (Ma et al., 2008). Briefly, a small $0.02-0.1 \mathrm{~cm}^{2}$ section of each quartz filter sample was inserted into a concentric glass liner, spiked with deuterated levoglucosan internal standard $(6.1 \mathrm{ng})$, and loaded into the TE unit [TDU, Gerstel Inc., Baltimore, MD]. The sample was heated [over $\mathrm{He}(50 \mathrm{~mL} / \mathrm{min})]$ from $25^{\circ} \mathrm{C}$ to $300^{\circ} \mathrm{C}$ at $20^{\circ} \mathrm{C} / \mathrm{min}$ and held for $10 \mathrm{~min}$. The TE unit was interfaced directly to the GC-MS (Model 6890-5973; Agilent Technologies) without a transfer line. So, thermally extracted sample was directed to and trapped in a cryocooled $\left(-30^{\circ} \mathrm{C}\right)$ programmable temperature vaporization
(PTV) inlet (Model CIS4; Gerstel Inc., Baltimore, MD). Following extraction, the inlet was flash heated $\left(720^{\circ} \mathrm{C} / \mathrm{min}\right)$ to $300^{\circ} \mathrm{C}$ transferring sample to the first dimension column (HP5-MS; $30 \mathrm{~m}$ length; $0.25 \mu \mathrm{m}$ film thickness; $0.25 \mathrm{~mm}$ i.d.; Agilent Technologies, Santa Clara, CA), which separated compounds by their volatility. In $2.4 \mathrm{~min}$, this column was heated to $300{ }^{\circ} \mathrm{C}\left(100^{\circ} \mathrm{C} / \mathrm{min}\right)$ and held for $7.5 \mathrm{~min}$. The He carrier gas flow rate was $1.5 \mathrm{~mL} / \mathrm{min}$. A $5 \% \mathrm{v} / \mathrm{v}$ fraction of this chromatographed sample was continuously routed to a flame ionization detector (FID). The FID chromatogram was used to plan the sample heartcutting events. A multi-column switching system (MCS; Gerstel Inc.) comprising a 5-way proportional valve and a cryogenic cooling and heating system (CTS) afforded computer-controlled, selective heart-cutting and trapping of the first dimension eluate. In this case, all GC-GC conditions were optimized for the rapid separation of the anhydro-sugar peaks of interest. The anhydro-sugars were thus sent to the second dimension column within 4 min of the beginning of the chromatographic run. Heart-cut eluate was trapped in a pre-column retention gap (deactivated fused silica capillary), which was connected to the proportional valve and passed through the cryo-cooled $\left(-50^{\circ} \mathrm{C}\right) \mathrm{CTS}$. Subsequent ballistic heating $\left(300^{\circ} \mathrm{C}\right.$ at $\left.20^{\circ} \mathrm{C} / \mathrm{s}\right)$ of the CTS directed the cut eluate to the shorter second dimension column (SolGel-Wax; $10 \mathrm{~m}$ length; $0.25 \mu \mathrm{m}$ film thickness; $0.25 \mathrm{~mm}$ i.d.; SGE Co., Austin, TX), which separated compounds by polarity. The temperature of the second column was fixed at $65^{\circ} \mathrm{C}$ for 4 min, raised to $225^{\circ} \mathrm{C}$ at $160^{\circ} \mathrm{C} / \mathrm{min}$, and then to $275^{\circ} \mathrm{C}$ at $40^{\circ} \mathrm{C} / \mathrm{min}$ and held for $3.75 \mathrm{~min}$. The He carrier gas flow rate through the second dimension column was $1.0 \mathrm{~mL} / \mathrm{min}$. Two modular accelerated column heaters (MACH, Gerstel Inc.) attached to the $\mathrm{GC}$ oven door provided the independent temperature control for each column with a maximum heating rate of $1800^{\circ} \mathrm{C} / \mathrm{min}$. The columns were wrapped in insulated heating tape with a temperature sensor wire. Integrated cooling fans ensured efficient air circulation and quick cooling. Compounds eluting from the second column were subject to electron ionization and measured with a qMS operating in scan mode. Several experiments were also performed in single ion monitoring mode (SIM) to examine the possibility of enhancing method sensitivity.

Standard mixtures containing the LG, MAN, GAL, and isotopically-labeled LG were prepared, subsequently diluted five times over a concentration range of $1 \mathrm{ng} / \mu \mathrm{L}-200 \mathrm{ng} / \mu \mathrm{L}$, and used for TE-GC-GC-MS instrument calibration. These diluted mixtures were also used to determine method detection and quantification limits (LOD and LOQ), reproducibility, recovery, linear dynamic range and carryover. Instrument calibration was performed in an empty glass extraction tube. A group of control tests indicated no significant difference between experiments conducted in the empty tube and those conducted in the presence of blank, pre-fired quartz fiber filters. 
Table 1. Summary of the validation parameters for the TE-GC-GC-MS method. Shown are the mean and standard deviation for $n=5$.

\begin{tabular}{llll}
\hline & LG & MAN & GAL \\
\hline recovery $(\%)$ & $92.3 \pm 2.8$ & $92.8 \pm 3.7$ & $91.7 \pm 6.4$ \\
carryover (\%) & $0.3 \pm 0.4$ & 0 & 0 \\
precision (\%) & 3 & 4 & 7 \\
overall method uncertainty $(\%)$ & 9 & 8 & 11 \\
limit of detection $(\mathrm{LOD})(\mathrm{ng} / \mu \mathrm{L})$ & 0.6 & 2.7 & 2.2 \\
limit of quantification $(\mathrm{LOQ})(\mathrm{ng} / \mu \mathrm{L})$ & 2.8 & 13.5 & 11.0 \\
linear dynamic range $(\mathrm{ng} / \mu \mathrm{L})$ & $2.8-200$ & $20-500$ & $20-250$ \\
\hline
\end{tabular}

\section{Results and discussion}

\subsection{Evaluation of TE-GC-GC-MS for fast, direct determination of anhydro-sugars}

Results of the TE-GC-GC-MS proficiency testing for the fast and direct quantification of anhydro-sugars are summarized in Table 1. Method recoveries of the anhydrous sugar compounds from the pre-conditioned quartz fiber filters spiked with $100 \mathrm{ng}$ of each authentic standard are consistently $90 \%$ or greater. In other words, there is less than $10 \%$ difference between the known target and method-determined concentrations, indicating high accuracy. Examination of chromatograms acquired immediately following the recovery analysis indicates negligible carryover. Over a 9-hr period, replicate $1 \mu \mathrm{L}$ injections $(n=5)$ of the $100 \mathrm{ng} / \mu \mathrm{L}$ MA standards onto quartz filters resulted in a TE-GC-GC-MS method precision of $3.0-7.0 \%$ RSD. An error propagation analysis that included the recovery, carryover, and reproducibility uncertainties shows an overall method precision of $8 \%-11 \%$ for anhydro-sugar concentrations measured above the limits of quantification (LOQ).

The LOQ is defined here as five times the limit of detection (LOD). The LOD is being defined as the minimum concentration of analyte that is measured and reported with $99 \%$ confidence at a concentration greater than zero. The LODs were determined using multiple $1 \mu \mathrm{L}$ injections of solutions containing $25 \mathrm{ng} / \mu \mathrm{L}$ MAN and GAL and $1 \mathrm{ng} / \mu \mathrm{L}$ LG. TEGC-GC-MS produces a lower LOD for $\mathrm{LG}(0.56 \mathrm{ng} / \mu \mathrm{L})$ than for either MAN $(2.7 \mathrm{ng} / \mu \mathrm{L})$ or GAL $(2.2 \mathrm{ng} / \mu \mathrm{L})$. With single ion monitoring, a roughly twofold increase in anhydrosugar response is observed. The calibration data given in Fig. 1 confirm the method's heightened response for LG and illustrate the linear working ranges adequate for measuring the anhydro-sugars in the biomass burning and atmospheric aerosols examined in the present study. The absolute linear dynamic range $\left(r^{2} \geq 0.99\right)$ for LG spans approximately two orders of magnitude. Despite a relatively lower TE-GC-GCMS response for MAN and GAL, higher maxima in the calibration interval are possible for these compounds, Table 1. Finally, we note that the anhydro-sugars were below detection limits on multiple analytical laboratory blanks. Further

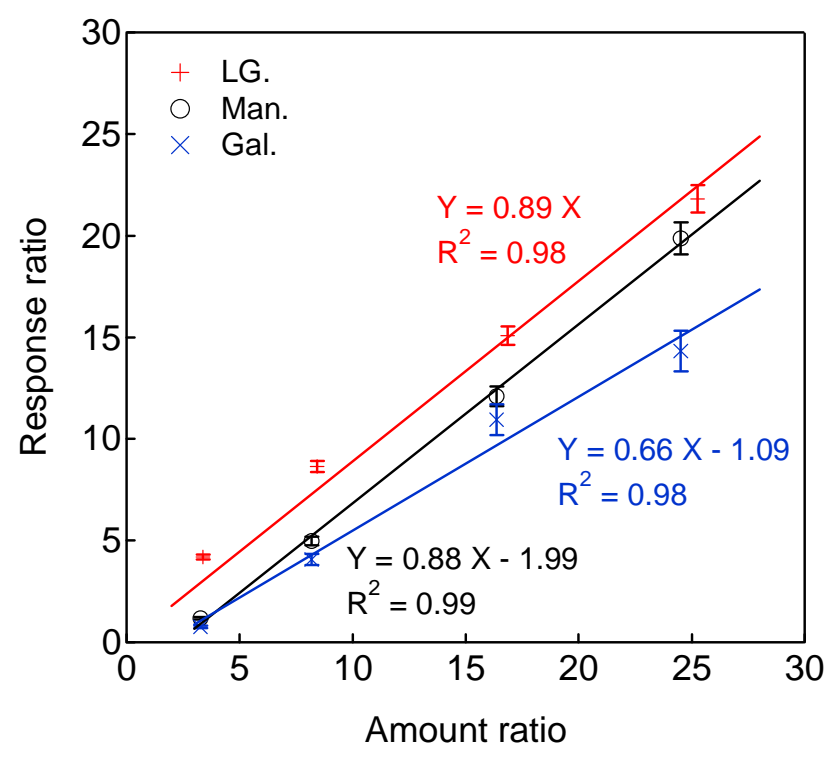

Fig. 1. Multi-level LG (+), MAN ( $\bigcirc)$, and GAL (X) calibration data with linear fit. All responses are normalized to deuterated LG internal standard $(6.1 \mathrm{ng} / \mu \mathrm{L})$.

discussion about how the method accuracy, precision, and sensitivity compare to established methods will be provided later.

\subsection{TE-GC-GC-MS application to PM samples}

Following validation, the TE-GC-GC-MS method was applied to biomass burning and atmospheric aerosol samples. As indicated, the biomass burning aerosol samples were collected from both live and simulated fires of differing intensity, using various field sampling techniques. The atmospheric aerosols were taken from independent geographic locations, expected to be impacted variously by biomass burning, and represented different PM size fractions. The samples were selected for the purpose of evaluating the TE-GC-GCMS method capability over a wide range of representative anhydro-sugar concentrations in aerosol matrixes important to air pollution studies. 
Table 2. Comparison of LG concentrations in biomass burning aerosols analyzed with SE-GC-MS and TE-GC-GC-MS methods (see Fig. 3). Shown are the mean and standard deviation based on triplicate analyses.

\begin{tabular}{lccc}
\hline PM sample & SE-GC-MS & TE-GC-GC-MS & TE/SE ratio \\
\hline \multicolumn{1}{c}{$\left(\%\right.$ of $\mathrm{PM}_{2.5}$ mass $)$} \\
$\begin{array}{l}\text { loblolly pine needles } \\
\text { (Pinus taeda) }\end{array}$ & $3.84 \pm 1.60$ & $4.19 \pm 0.12$ & 1.09 \\
$\begin{array}{l}\text { rice straw } \\
\text { (Oryza sativa })\end{array}$ & $8.87 \pm 0.46$ & $8.53 \pm 0.66$ & 0.96 \\
$\begin{array}{l}\text { wheat straw } \\
\text { (Triticum aestivum })\end{array}$ & $2.63 \pm 0.15$ & $2.36 \pm 0.05$ & 0.90 \\
$\begin{array}{l}\text { forest litter mixture }-\mathrm{CNF} \\
\text { (Pinus and Quercus sp. })\end{array}$ & $8.98 \pm 0.90$ & $7.94 \pm 0.62$ & 0.88 \\
\hline
\end{tabular}
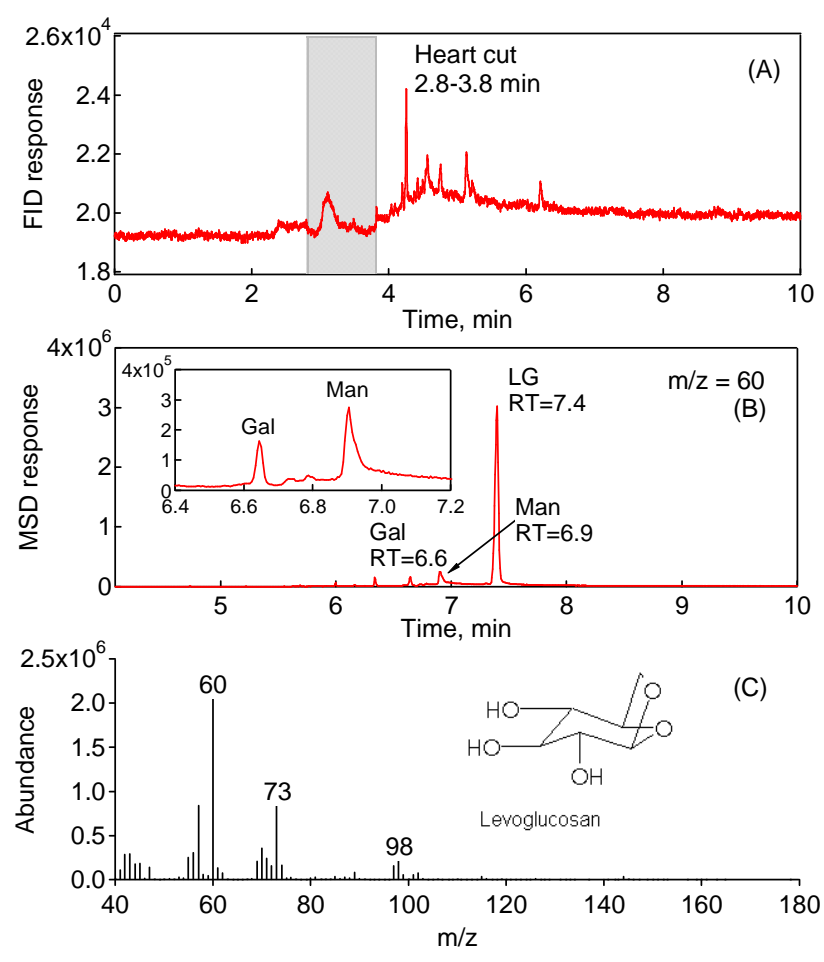

Fig. 2. TE-GC-GC-MS analysis of $\mathrm{PM}_{2.5}$ filter sample collected in NC piedmont region (PMT). (a) FID response and selected 1 min (2.8-3.8 min) heart-cut region in grey. (b) Extracted ion chromatogram at $m / z=60$ following the second dimension separation. Retention times of each anhydro-sugar are labeled. Inset shows the mannosan and galactosan at a resolution (Rs) $>3$; Rs values $>1.5$ indicate full resolution. (c) Mass spectrum of LG obtained at a retention time of $7.4 \mathrm{~min}$.

\subsubsection{Representative TE-GC-GC-MS heart-cutting}

Figure 2 exhibits a typical TE-GC-GC-MS analysis using the PMT sample. Panel A in the figure shows the flame ionization detector (FID) response following the first dimension separation; the grey reference area indicates the $1 \mathrm{~min}$ heart- cut region (2.8-3.8 $\mathrm{min})$ over which the anhydro-sugars are targeted for transfer to the second dimension column. Narrower heart-cut transfers are not possible due to observed loss of target compound mass. Panel B shows the second dimension ion chromatogram at $m / z=60$, the target ion for the anhydro-sugars. Underivatized LG appears as a narrow Gaussian peak at retention time (RT) $7.4 \mathrm{~min}$ in the 2-D chromatogram, fully separated from the minor MAN $(\mathrm{RT}=6.6 \mathrm{~min})$ and $\mathrm{GAL}(\mathrm{RT}=6.9 \mathrm{~min})$ isomers $\left(\mathrm{C}_{6} \mathrm{H}_{10} \mathrm{O}_{5}\right)$ in the complex fire sample in a chromatographic run time of less than $10 \mathrm{~min}$. The LG mass spectrum obtained from PMT (Fig. 2, panel C) was positively confirmed against the National Institute of Standards and Technology spectral library.

\subsubsection{Comparison of SE-GC-MS and TE-GC-GC-MS results for LG in biomass burning aerosols}

Of the eight aerosol samples examined in the present study, four (Pinus taeda, Oryza sativa, Triticum aestivium, and CNF) also underwent GC-MS analysis following the trimethylsilyl derivatization of solvent-extract (Hays et al., 2002; Hays et al., 2005). Archived filter samples from these earlier tests presented a unique opportunity to contrast the current TE-GC-GC-MS method with a more conventional SE-GC-MS analysis being widely used for organic marker speciation. Authentic GAL and MAN standards were unavailable at the time the SE-GC-MS method was applied to the biomass burning samples (Pinus taeda, Oryza sativa, and Triticum aestivium) collected from the enclosure (20002001); thus, only LG results are presented.

Figure 3 shows TE-GC-GC-MS and SE-GC-MS LG concentrations normalized to fine PM mass; for the four biomass burning samples, the LG levels range from 3-9\% of the PM (Table 2). The error bars reflect one standard deviation based on triplicate analyses. We can only speculate on why the error for loblolly pine is greater. We have no knowledge of an interfering matrix compound per se. However, silyated $\mathrm{LG}$ at high concentrations can cause interference at $\mathrm{m} / \mathrm{z}$ 


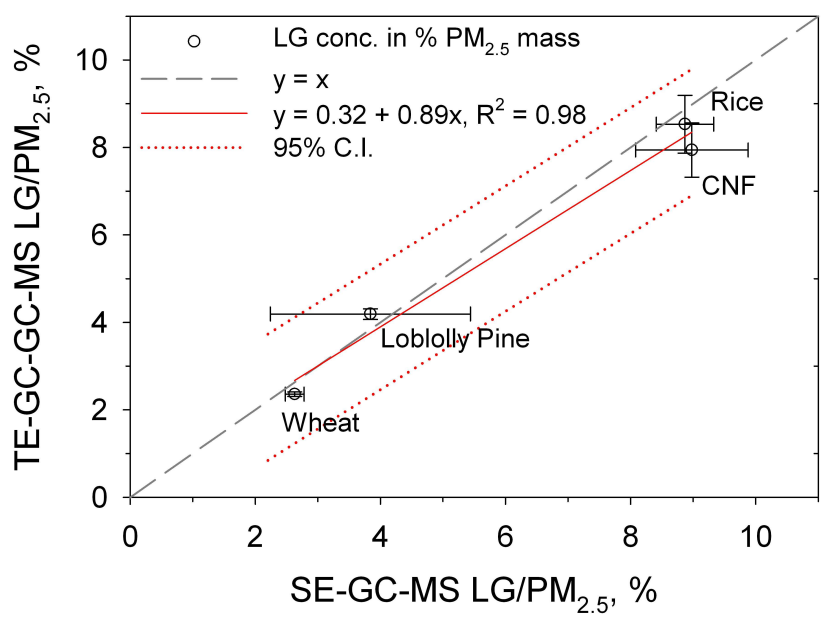

Fig. 3. Comparison of SE-GC-MS and TE-GC-GC-MS-determined LG concentrations [LG/PM 2.5 mass (w/w)] in four unique biomass burning aerosols. The reduced major axis linear fit (solid line), 95\% confidence band (dotted lines), and 1:1 line (long dashed line forced through $(0,0)$ are shown. The error bars reflect one standard deviation based on triplicate analyses.

206, which is the base peak target assigned to the silyated ${ }^{13} \mathrm{C}$-LG internal standard for this test. Checks with standards indicated that this was a nearly negligible issue for our instrument within our calibration range at the time the loblolly pine analysis was conducted. Perhaps the biomass burning matrix was inadequately modeled by checking only standards. We also note that the solvent extraction-GC-MS analysis of the loblolly pine and CNF fire emissions, which show higher error, did occur in a different analytical laboratory than the wheat and the rice straw burns. The TE error is lower due to the automated nature of the procedure, and for TE, MS peak integration and quantification is confirmed with both primary base peak and secondary qualifier ions, which removes this interference from LG. Finally, TE replicates use small filter pieces from the same filter while trials for SE include different filters collected in parallel; thus, filter sample inhomogeneities and differences in how the filters are used are other variables that can contribute to differences in error among these samples and methods. In the figure, the data are fit using a reduced major axis linear regression to account for the fact that both the $X$ and $Y$ variables contain error. The result is a TE/SE LG concentration ratio near unity, $m=0.89 \pm$ 0.09 and $r^{2}=0.98$. Implicit from the slightly negative TE bias is the adsorption of the more polar untreated LG onto the TE hardware, GC inlet or column surfaces. Moreover, minor thermal alteration of LG to further dehydrated levoglucosenone may be possible. However, the TE/SE LG concentration ratio among the samples is $0.96 \pm 0.09$ on average, Table 2, and the emissions data are well within the demarcated linear confidence interval at $\alpha=0.05$. This agreement is remarkable considering the TE-GC-GC-MS and SE-GC-MS analyses took place nearly one decade apart with different instruments, chromatographic techniques, chemical standards, and analysts. The agreement also further verifies the relative accuracy of the TE-GC-GC-MS method in the presence of the biomass burning matrix. Finally, these data strongly suggest that LG in filter-collected biomass burning aerosols is stable for up to $8 \mathrm{yr}$ in ultra-low temperature $\left(-40\right.$ to $\left.-50^{\circ} \mathrm{C}\right)$ storage.

\subsubsection{Anhydro-sugar concentrations in simulated and near-source biomass burning samples}

Table 3 presents the TE-GC-GC-MS-determined anhydrous sugar concentrations in three simulated (Pinus taeda, Oryza sativa, and Triticum aestivium) and two near-source (CNF and PMT) biomass burning samples. The LG:MAN:GAL ratio in the PM mixture is roughly 15:2:1 on average. This ratio should directly reflect the proportion of D-glucose and mannose and galactose precursor residues in the plant cellulose and hemicellulose, respectively, although plant hemicellulose does contain some glucose. Schmidl et al. (2009) recently alluded to the use of the relative proportion of the anhydro-sugars for differentiating hard- and soft-wood emissions using commonly burned tree species native to midEuropean alpine regions. The results for Pinus taeda (3.7), CNF (4.6), and PMT (4.6) samples support their conclusion that Gymnosperm species produce relatively lower LG to MAN ratios between 3.6-3.9. Angiosperm trees interspersed throughout pine forests likely partly explain the slightly higher ratios observed for the CNF and PMT samples. Moreover, the hemicellulose polysaccharides generally degrade at a faster rate, and decaying plant matter on the forest surface burned during the CNF and PMT tests (McLaren et al., 1967). The substantially higher values of 20.8 and 15.6 corresponding to the combustion of Oryza sativa, and Triticum aestivium may also indicate the degradation of hemicellulose matter as these biomass samples were dry stored prior to burning (Hays et al., 2005). The proportion of cellulose to hemicellulose also changes with plant species as does the galactose to mannose ratio contained in hemicellulose; thus, care must be taken when interpreting anhydro-sugar marker ratios in atmospheres impacted by forest fires that consume a mixture of fresh and aged vegetational species.

As expected, the near-source CNF and PMT samples that underwent atmospheric dilution show lower PM and anhydro-sugar mass per unit volume of air sampled than those from the enclosure fires. However, these different sampling and burn modes return a comparable fraction of LG in PM (6-8\% versus 2-9\%). Although not the focus here, this result suggests that dilution sampling from a combustion experiment within an enclosure can adequately mimic near-source sampling with atmospheric dilution for LG measurement. In addition, the 5.8\% w/w LG in the PMT aerosol shows that despite its low intensity, the fire was the major $\mathrm{PM}_{2.5}$ contributor to this sample. Overall, the anhydro-sugar 
Table 3. Anhydro-sugar concentrations in a variety of biomass burning and atmospheric aerosol samples $(n=3)$.

\begin{tabular}{|c|c|c|c|c|c|c|c|}
\hline Sample & PM mass & LG & MAN & GAL & total AS & LG/AS & LG/PM \\
\hline & \multicolumn{5}{|c|}{$\left(\mu \mathrm{g} / \mathrm{m}^{3}\right)$} & \multicolumn{2}{|c|}{$(\%)$} \\
\hline \multicolumn{8}{|c|}{ Enclosure-simulated biomass burning ${ }^{\mathrm{a}}$} \\
\hline loblolly pine & 9242 & $387.2 \pm 11.0$ & $104.8 \pm 9.1$ & $36.0 \pm 1.2$ & $528.0 \pm 51.1$ & $73.3 \pm 7.4$ & $4.2 \pm 0.1$ \\
\hline rice straw & 3810 & $324.8 \pm 25.0$ & $15.6 \pm 0.6$ & $11.0 \pm 0.3$ & $351.4 \pm 31.1$ & $92.4 \pm 10.9$ & $8.5 \pm 0.7$ \\
\hline wheat straw & 990.0 & $23.4 \pm 0.5$ & $1.5 \pm 0.02$ & NA & $24.9 \pm 0.6$ & $93.9 \pm 3.2$ & $2.4 \pm 0.1$ \\
\hline \multicolumn{8}{|c|}{ Near-source sampling of prescribed burning and wildfire ${ }^{b}$} \\
\hline $\mathrm{CNF}$ & 682.5 & $54.2 \pm 4.3$ & $11.7 \pm 1.3$ & $7.4 \pm 2.5$ & $73.3 \pm 26.7$ & $74.0 \pm 27.6$ & $7.9 \pm 0.6$ \\
\hline PMT & 39.6 & $2.3 \pm 0.1$ & $0.5 \pm 0.02$ & $0.2 \pm 0.003$ & $3.0 \pm 0.2$ & $76.7 \pm 5.7$ & $5.8 \pm 0.3$ \\
\hline \multicolumn{8}{|c|}{ US and African atmospheric aerosols ${ }^{\mathrm{c}}$} \\
\hline KNY01 & 162 & $1.4 \pm 0.1$ & $0.2 \pm 0.03$ & $0.1 \pm 0.03$ & $1.7 \pm 0.6$ & $82.4 \pm 28.8$ & $0.8 \pm 0.06$ \\
\hline KNY02 & 225 & $0.3 \pm 0.1$ & $0.04 \pm 0.04$ & $0.04 \pm 0.04$ & $0.4 \pm 0.6$ & $78.9 \pm 117.7$ & $0.1 \pm 0.04$ \\
\hline KSV & 131 & $0.01 \pm 0.01$ & - & - & $0.01 \pm 0.01$ & - & $0.004 \pm 0.004$ \\
\hline
\end{tabular}

a Open burning simulations were performed from February 2000 to August 2001 in an enclosure as described in Hays et al. (2002, 2005). For these tests, accumulation mode fine aerosol emissions were collected using the dilution sampler described in Hildemann et al. (1989). ${ }^{\mathrm{b}}$ Near source prescribed burning and wildfire samples were collected at Croatan National Forest (CNF) and Piedmont area (PMT) of NC, USA using a hi-volume dichotomous sampler; the PM 2.5 fraction was examined for this study. ${ }^{\mathrm{c}}$ Aerosol was collected for $24 \mathrm{~h}$ in Nairobi, Kenya (KNY) on August 2006 and October 2006 with a high-volume sampler using a cut-off diameter of $35 \mu \mathrm{m}$. Additional notes: A dash indicates either that the compound is below detection limits or the ratio is not applicable. Mean and one standard deviation are reported based on $n=3$.

concentration range being reported here on a PM mass basis $(\mathrm{w} / \mathrm{w})$ is well within that reported for biomass burning to date as evidenced by panel A in Fig. 4 (Caseiro et al., 2009).

\subsubsection{Anhydro-sugar concentrations in atmospheric aerosols}

Table 3 provides the TE-GC-GC-MS determined anhydrosugar concentrations in the three atmospheric aerosol samples - KNY01, KNY02, and KSV. The absence of MAN and GAL and scant $\mathrm{LG}\left(0.01 \mu \mathrm{g} \mathrm{m}^{-3}\right)$ in the $24 \mathrm{~h} \mathrm{KSV}$ aerosol is consistent with a rural North Carolina agricultural area where burning activity was limited. Relatively speaking, African aerosols KNY01 and KNY02 comprise both MAN and GAL and at least an order of magnitude more LG. As discussed, Fig. 4, panel B compares our LG concentrations to those measured previously in a variety of aerosols collected globally using different analysis techniques. Although the concentration of LG in atmospheric PM can vary with many factors including meteorology, geographic region, and monitoring site proximity to biomass burning sources, LG concentrations in the atmospheric aerosols examined for the present study are well within range of published values (0.004$\left.7.6 \mu \mathrm{g} / \mathrm{m}^{3}\right)$. LG enrichment over the accumulation mode in biomass burning $\mathrm{PM}_{2.5}$ is expected (Fine et al., 2004). For KNY01 and KNY02, Table 3 gives $\mathrm{PM}_{35}$ enrichment $(w / w)$ that would substantially increase if only $\mathrm{PM}_{2.5}$ mass were being considered, suggesting a substantial contribution from the domestic burning of biomass and waste in urban Nairobi. In sum, TE-GC-GC-MS is also suitable for anhydro-sugar determination in atmospheric aerosol matrixes containing different particle size distributions and variably impacted by biomass smoke. Note for the Kenyan aerosols that visual inspection of spent filters following thermo-chemical measurements revealed a substantial crustal or dust component commonly assigned to a coarse mode.

\subsection{Comparisons with other analytical methods}

Next, the advantages and disadvantages of quantitative analytical methods for LG are briefly discussed with regard to practical TE-GC-GC-MS application. As with Fig. 4, this discussion is confined primarily to $\mathrm{LG}$ as it is a leading focus of biomass burning related air quality studies currently.

\subsubsection{Overall method analysis times}

Retention times for LG with conventional GC-MS methods normally exceed 20 minutes (Zdrahal et al., 2002; Wan et al., 2007; Williams et al., 2006). HPLC and IC analyses are generally more rapid (Dye et al., 2005; Engling et al., 2006; Engling et al., 2006; Schkolnik et al., 2005). LG elutes in less than 2 min with some HPLC tandem MS and CE-PAD methods (Gambaro et al., 2008; Garcia et al., 2005). The use of flow injection to directly introduce sample to an MS detector is even faster but the lack of selectivity confounds identification of the anhydro-sugar isomers and can complicate experimental MS-MS results (Gao et al., 2003). While fast, aerosol sample handling and pretreatment for these techniques typically require a minimum of $1 \mathrm{~h}$ and often as much as $24 \mathrm{~h}$ 

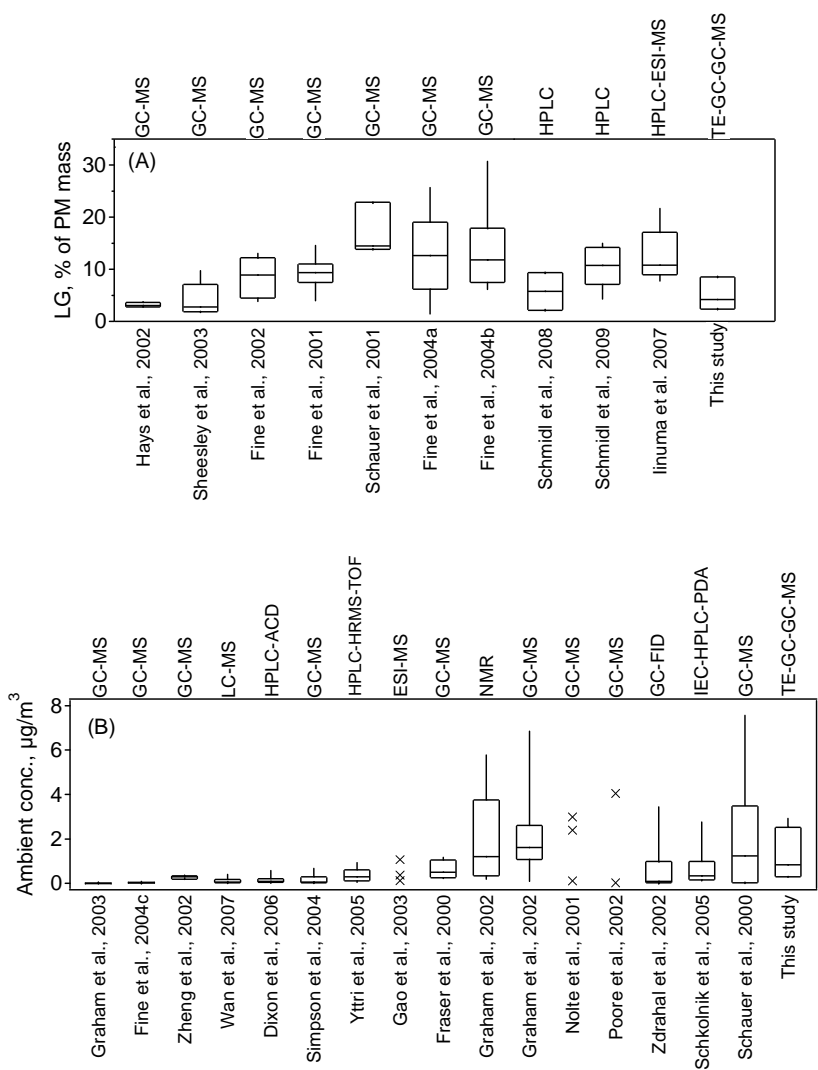

Fig. 4. Literature-reported LG concentrations compared to those of the present study. (a) LG concentrations measured during biomass burning source tests with variable biomass fuel types and analytical techniques (\% PM mass). The bottom, middle, and top of the box plots correspond to the 25,50 , and 75 percentile of each data set; the bottom and top of the whiskers indicate the 10 and 90 percentiles, respectively. (b) Analytical method-based LG concentrations $\left(\mu \mathrm{g} / \mathrm{m}^{3}\right)$ in ambient atmospheric aerosols collected globally. Studies with limited data sets precluding box plot creation are indicated by $\mathrm{X}$ symbols, which are the data points available for that particular study.

depending on the exact extraction, filtration, or derivatization procedures being utilized. On the other hand, the TE step requires $25 \mathrm{~min}$ or less, and the anhydro-sugars elute within $7.4 \mathrm{~min}$ using fast chromatography. This $32 \mathrm{~min}$ run time may be decreased even further by shortening first and second dimension column lengths or changing the TE temperature program. Contingent on the number of samples, and sample preparation steps and analysis times, the TE-GC-GCMS method affords up to an approximately two-fold increase in laboratory throughput over most currently available methods that speciate LG in aerosols. Of course, as the ability to perform batch solvent extractions in parallel increases, the throughput advantage of TE may lessen depending on the exact instrumental approach being taken.

\subsubsection{Extraction and recovery efficiency}

Method recovery or relative accuracy is defined here as the difference between a known, fixed concentration of target analyte spiked onto a blank filter and the analytical methoddetermined concentration. The TE-GC-GC-MS method LG recovery is $\geq 90 \%$, which is at the top-end of the performance range for accuracy presently. In the literature, analyticalchemical method recoveries for LG generally vary from $69 \%$ to $99 \%$ (Gambaro et al., 2008; Zdrahal et al., 2002; Pashynska et al., 2002; Dye et al., 2005; Simpson et al., 2004; Schkolnik et al., 2005). Sample filtration, concentration, and derivatization steps appear common to chromatography studies that report high recoveries (Schkolnik et al., 2006; Pashynska et al., 2002); although, the choice of solvent mixture and internal standard may influence these values. For example, dichloromethane-acetic acid extracts evaporated to dryness and reconstituted and derivatized in pyridine without an isotopically-labelled anhydro-sugar internal standard tended to yield low recoveries for LG (Zdrahal et al., 2002). Low recoveries were also observed following the GC-MS analysis of ethylacetate-triethylamine extracts despite them containing a 1,5-anhydro-D-mannitol internal standard and being derivatized (Simpson et al., 2004). In contrast, extractions with water, tetrahydrofuran, or a dichloromethanemethanol mixture $(80: 20, \mathrm{v} / \mathrm{v})$ recover greater than $90 \%$ LG when using ion-exclusion chromatography (IEC) - HPLC - photodiode array (PDA) (Schkolnik et al., 2005), HPLCESI-high resolution MS (Dye et al., 2005), and GC-MS-MS (Pashynska et al., 2002) instrumentation, respectively.

\subsubsection{Sensitivity}

Instrumental limit of detection (LOD) is an important factor used to assess method sensitivity. For comparison purposes, the authors explored the possibility of reporting sensitivity for all methods as a function of total extracted and injected analyte or aerosol mass. However, a literature inspection revealed that many of the studies being compared did not always provide the total aerosol mass or LG extracted, injection volume, or final concentrated volume values needed to perform the conversion. LOD units of ng/ $\mu \mathrm{L}$ or similar were most frequently available; thus, these units are used here for comparison purposes in an effort to be consistent. For GC-qMS, the LOD for LG is typically $0.1 \mathrm{ng} / \mu \mathrm{L}$ or less (Simpson et al., 2004). LC-MS methods typically achieve low picogram LODs. For example, Dye and Yittry (2005) observe $0.03 \mathrm{ng} / \mu \mathrm{L}$ using LC-ESI-TOFMS technique, Wan and Yu (2007) use LC-qMS with postcolumn chlorine addition for enhanced analyte-adduct formation and report $0.014 \mathrm{ng} / \mu \mathrm{L}$, while Gambaro et al. (2008) with LC-qqqMS see an LOD of $0.003 \mathrm{ng} / \mu \mathrm{L}$ albeit with comparatively low precisions of $20 \%$ to $50 \%$ RSD. Among the fastest for LG, high-performance anion-exchange chromatography with PAD is also quite responsive showing a 
LOD of $0.002 \mathrm{ng} / \mu \mathrm{L}$ (Engling et al., 2006). At first glance, TE-GC-GC-MS appears somewhat less sensitive for LG (Table $1, \mathrm{LOD}=0.6 \mathrm{ng} / \mu \mathrm{L}$ ). However, a fair comparison among techniques should also consider that TE is a whole-sampling method. In contrast, most IC, LC, and SE-GC-MS methods inject a $1-25 \mu \mathrm{L}$ aliquot that is only a fraction of the total PM in the liquid extract (which is typically $250 \mu \mathrm{L}$ or more for GC-MS methods, for example), reducing the effective sensitivity of these methods. Many solvents are not concentrated below these levels due to background and contamination issues. Considering this factor, the effective TE-GC-GC-MS sensitivity for LG in aerosol matter improves by as much as two orders of magnitude, which places TE-GC-GC-MS among the most sensitive methods for LG in aerosol matter.

\subsubsection{Precision}

Differences in precision or reproducibility among methods are evaluated here using relative standard deviation, which is the standard deviation of a measurement set $(n \geq 3)$ divided by the mean and multiplied by $100 \%$. This value includes method uncertainty and contributions to variability such as inconsistencies in internal and calibration standard spike and injection volumes, instrumentation and peak integration error, and filter sample inhomogeneities. For matrix blank spikes and most biomass burning and atmospheric aerosol samples, the TE-GC-GC-MS precision varied from 3\% to $8 \%$ RSD. As expected, this value is inversely proportional to the anhydro-sugar concentration in the aerosol. Literature values of LG measurement precision depend on the method applied. For example, the range of reproducibility values reported for GC-MS studies (most with derivatization) is consistently 2-20\% RSD (Graham et al., 2003; Simpson et al., 2004; Graham et al., 2002). For HPAEC-PAD, and HPLCaerosol charge detection (ACD), corresponding precisions of 5.3\% and 6.7\% RSD are observed (Engling et al., 2006; Dixon et al, 2006). Generally, the lower reported RSDs are due to replicate (same sample) extract injections as opposed to different extraction trials. Elimination of sample loss and automation of the direct thermal extraction step potentially explain the high precisions observed for TE-GC-GC-MS. In addition, further separation of narrow heart-cut sections of the aerosol sample reduces on-column sample load, matrix background, and the probability of co-detection, all of which are likely to improve peak shape, resolution, and stabilize the MS detector response.

\section{Conclusions}

A fast two-dimensional GC-MS method with thermal extraction was developed for trace quantification of anhydro-sugars in biomass burning and atmospheric aerosols. Anhydrosugar stereoisomers were fully extracted and resolved within $30 \mathrm{~min}$. Using $\mathrm{m} / \mathrm{z} 60$ as the target quantification ion, high average relative accuracies and precisions for the anhydrosugars were achieved. A comparative analysis across a limited set of biomass burning aerosols showed that TE-GC-GCMS results compared well to those obtained using conventional SE-GC-MS and that LG is stable in ultra-low temperature storage for at least 8 years. The method can be successfully applied to aerosol matrixes characterizing background air, weak or intensive biomass burning, or heavily polluted urban environments. Saccharides and other polar organic constituents can also be identified and quantified with the same technique (Ma et al., 2008); only slight changes in the TE-GC-GC-MS heart-cut intervals are likely to produce additional information about $n$-alkanoic acids, substituted phenols, and nitrogen-bearing heterocyclics in biomass burning aerosols. Finally, we anticipate that this method is likely to even further enhance the sample throughput and thus temporal resolution of aerosol marker chemistry for improved source apportionment and understanding of epidemiological and health effects data.

Acknowledgements. This project was supported in part by Yilin Ma's appointment to the Research Participation Program at the US Environmental Protection Agency, administered by the Oak Ridge Institute for Science and Education through an interagency agreement between the US Department of Energy and EPA. International Programs in the Physical Sciences (IPPS) at Uppsala University, Sweden, supported the field sampling campaigns in Nairobi, Kenya through the support program for INST, University of Nairobi. The authors also thank Jeff Collett's research group at Colorado State University for supplying the galactosan standard. The authors also acknowledge partial support by the Joint Fire Sciences Research Program. Bob Mickler of Alion Science assisted in field sample collection.

Edited by: H. Moosmuller

\section{References}

Branca, C., Giudicianni, P., and Di Blasi, C.: GC/MS characterization of liquids generated from low-temperature pyrolysis of wood, Ind. Eng. Chem. Res., 42(14), 3190-3202, 2003.

Caseiro, A., Bauer, H., Schmidl, C., Pio, C. A., Puxbaum, H.: Wood burning impact on PM10 in three Austrian regions, Atmos. Environ., 43, (13), 2186-2195, 2009.

Chow, J. C., Yu, J. Z., Watson, J. G., Ho, S. S. H., Bohannan, T. L., Hays, M. D., and Fung, K. K.: The application of thermal methods for determining chemical composition of carbonaceous aerosols: A review, J. Environ. Sci. Health A., 42, (11), 15211541, 2007.

Dixon, R. W. and Baltzell, G.: Determination of levoglucosan in atmospheric aerosols using high performance liquid chromatography with aerosol charge detection, J. Chromatogr. A, 1109, 214 221, 2006.

Dye, C. and Yttri, K. E.: Determination of monosaccharide anhydrides in atmospheric aerosols by use of high-performance liquid chromatography combined with high-resolution mass spectrometry, Anal. Chem., 77, 1853-1858, 2005. 
Elias, V., Simoneit, B., Cordeiro, R., and Turcq, B.: Evaluating levoglucosan as an indicator of biomass burning in Carajas, Amazonia: A comparison to the charcoal record, Geochim. Cosmochim. Acta, 65, 267-272, 2001.

Engling, G., Carrico, C. M., Kreidenweis, S. M., Jeffrey L. Collett, J., Day, D. E., Malm, W. C., Lincoln, E., Hao, W. M., Iinuma, Y., and Herrmann, H.: Determination of levoglucosan in biomass combustion aerosol by high-performance anion-exchange chromatography with pulsed amperometric detection, Atmos. Environ., 40, 299-311, 2006.

Falkovich, A. H. and Rudich, Y.: Analysis of semivolatile organic compounds in atmospheric aerosols by direct sample introduction thermal desorption GC/MS, Environ. Sci. Technol., 35(11), 2326-2333, 2001.

Fine, P. M., Cass, G. R., and Simoneit, B. R. T.: Chemical Characterization of Fine Particle Emissions from Fireplace Combustion of Woods Grown in the Northeastern United States, Environ. Sci. Technol., 35(13), 2665-2675, 2001.

Fine, P. M., Cass, G. R., and Simoneit, B. R. T.: Chemical characterization of fine particulate emissions from the fireplace combustion of woods grown in the southern United States, Environ. Sci. Technol., 36, 1442-1451, 2002.

Fine, P. M., Cass, G. R., and Simoneit, B. R. T.: Chemical characterization of fine particulate emissions from the fireplace combustion of woods grown in the midwestern and western United States, Environ. Eng. Sci., 21, 387-409, 2004a.

Fine, P. M., Cass, G. R., and Simoneit, B. R. T.: Chemical characterisation of fine particle emissions from the wood stove combustion of prevalent United States tree species, Environ. Eng. Sci., 21, 705-721, 2004b.

Fine, P. M., Chakrabarti, B., Krudysz, M., Schauer, J. J., and Sioutas, C.: Diurnal variations of individual organic compound constituents of ultrafine and accumulation mode particulate matter in the Los Angeles basin, Environ. Sci. Technol., 38, 12961304, 2004c.

Fraser, M. and Lakshmanan, K.: Using levoglucosan as a molecular marker for the long-range transport of biomass combustion aerosols, Environ. Sci. Technol., 34(21), 4560-4564, 2000.

Gambaro, A., Zangrando, R., Gabrielli, P., Barbante, C., and Cescon, P.: Direct Determination of Levoglucosan at the Picogram per Milliliter Level in Antarctic Ice by HighPerformance Liquid Chromatography/Electrospray Ionization Triple Quadrupole Mass Spectrometry, Anal. Chem., 80(5), 1649-1655, 2008.

Gao, S., Hegg, D. A., Hobbs, P. V., Kirchstetter, T. W., Magi, B. I., and Sadilek, M.: Water-soluble organic components in aerosols associated with savanna fires in southern Africa: identification, evolution, and distribution, J. Geophys. Res., 108(D13), 8491, doi:10.1029/2002JD002324, 2003.

Garcia, C. D., Engling, G., Herckes, P., Collett, J. L., and Henry, C. S.: Determination of levoglucosan from smoke samples using microchip capillary electrophoresis with pulsed amperometric detection, Environ. Sci. Technol., 39, 618-623, 2005.

Graham, B., Guyon, P., Taylor, P., Artaxo, P., Maenhaut, W., Glovsky, M., Flagan, R., and Andreae, M.: Organic compounds present in the natural Amazonian aerosol: Characterization by gas chromatography-mass spectrometry, J. Geophys. Res. Atmos., 108(D24), 4677, doi:10.1029/2003JD003990, 2003.

Graham, B., Mayol-Bracero, O., Guyon, P., Roberts, G., Dece- sari, S., Facchini, M., Artaxo, P., Maenhaut, W., Koll, P., and Andreae, M.: Water-soluble organic compounds in biomass burning aerosols over Amazonia 1. Characterization by NMR and GC-MS, J. Geophys. Res., 107(D20), 8047, doi:10.1029/2001JD000336, 2002.

Gravitis, J., Zandersons, J., Vedernikov, N., Kruma, I., and OzolsKalnins, V.: Clustering of bio-products technologies for zero emissions and eco-efficiency, Ind. Crops Products, 20, 169-180, 2004.

Hamilton, J. F., Webb, P. J., Lewis, A. C., Hopkins, J. R., Smith, S., and Davy, P.: Partially oxidised organic components in urban aerosol using GCXGC-TOF/MS, Atmos. Chem. Phys., 4, 12791290, 2004, http://www.atmos-chem-phys.net/4/1279/2004/.

Hays, M. D., Fine, P. M., Geron, C. D., Kleeman, M. J., and Gullett, B. K.: Open burning of agricultural biomass: Physical and chemical properties of particle-phase emissions, Atmos. Environ., 39, 6747-6764, 2005.

Hays, M. D., Geron, C. D., Linna, K. J., Smith, N. D., and Schauer, J. J.: Speciation of gas-phase and fine particle emissions from burning of foliar fuels, Environ. Sci. Technol., 36(11), 22812295, 2002.

Hays, M. D., N. D. Smith, J. Kinsey, Y. Dong, and P. H. Kariher: Polycyclic aromatic hydrocarbon size distribution in aerosols from appliances of residential wood combustion as dertermined by direct thermal desorption-GC/MS, J. Aerosol Sci., 34, 10611084, 2003.

Hildemann, L. M., Cass, G. R., and Markowski, G. R.: A dilution stack sampler for collection of organic aerosol emissions: design, characterization and field tests, Aerosol Sci. Technol., 10, 193204, 1989.

Hope, J. L., Prazen, B. J., Nilsson, E. J., Lidstrom, M. E., and Synovec, R. E.: Comprehensive two-dimensional gas chromatography with time-of-flight mass spectrometry detection: analysis of amino acid and organic acid trimethylsilyl derivatives, with application to the analysis of metabolites in rye grass samples, Talanta, 65(2), 380-388, 2005.

Iinuma, Y., Brueggemann, E., Gnauk, T., Mueller, K., Andreae, M. O., Helas, G., Parmar, R., and Herrmann, H.: Source characterization of biomass burning particles: the combustion of selected European conifers, African hardwood, savanna grass, and German and Indonesian peat, J Geophys. Res., 112(D8), D08209/1D08209/26, 2007.

Kallio, M., Hyötyläinen, T., Lehtonen, M., Jussila, M., Hartonen, K., Shimmo, M., and Riekkola, M.-L.: Comprehensive two-dimensional gas chromatography in the analysis of urban aerosols, J. Chromatogr. A, 1019, 251-260, 2003.

Kituyi, E., Marufu, L., Huber, B., Wandiga, S. O., Jumba, I. O., Andreae, M. O., and Helas, G.: Biofuel consumption rates and patterns in Kenya, Biomass Bioener., 20, 83-99, 2001.

Kleeman, M. J., Robert, M. A., Riddle, S. G., Fine, P. M., Hays, M. D., Schauer, J. J., and Hannigan, M. P.: Size distribution of trace organic species emitted from biomass combustion and meat charbroiling, Atmos. Environ., 42(13), 3059-3075, 2008.

Lin, L., Lee, M. L., and Eatough, D. J.: Gas chromatographic analysis of organic marker compounds in fine particulate matter using solid-phase microextraction, J. Air Waste Manage. Assoc., 57, 53-58, 2007.

Ma, Y. and Hays, M. D.: Thermal extraction-two-dimensional gas chromatography-mass spectrometry with heart-cutting for nitro- 
gen heterocyclics in biomass burning aerosols, J. Chromatogr. A, 1200(2), 228-234, 2008.

McLaren, A. D. and Peterson, G. H. (Eds.): Soil Biochemistry, Dekker, New York, USA, 509 pp., 1967.

Migliaccio, C. T., Bergauff, M. A., Palmer, C. P., Jessop, F., Noonan, C. W., and Ward, T. J.: Urinary levoglucosan as a biomarker of wood smoke exposure: observations in a mouse model and in children, Environ. Health Perspect., 117(1), 74-79, 2009.

Nolte, C. G., Schauer, J. J., Cass, G. R., and Simoneit, B. R. T.: Trimethylsilyl Derivatives of organic compounds in source samples and in atmospheric fine particulate matter, Environ. Sci. Technol., 35, 1912-1919, 2001.

Otto, A., Gondokusumo, R., and Simpson, M. J.: Characterization and quantification of biomarkers from biomass burning at a recent wildfire site in Northern Alberta, Canada. Appl. Geochem., 21(1), 166-183, 2006.

Pashynska, V., Vermeylen, R., Vas, G., Maenhaut, W., and Claeys, M.: Development of a gas chromatographic/ion trap mass spectrometric method for the determination of levoglucosan and saccharidic compounds in atmospheric aerosols. Application to urban aerosols, J. Mass Spectrom., 37, 1249-1257, 2002.

Poore, M. W.: Levoglucosan in PM2.5 at the fresno supersite, J. Air Waste Manage. Assoc., 52, 3-4, 2002.

Schauer, J. J. and Cass, G. R.: Source apportionment of wintertime gas-phase and particle-phase air pollutants using organic compounds as tracers, Environ. Sci. Technol., 34, 1821-1832, 2000.

Schauer, J. J., Kleeman, M. J., Cass, G. R., and Simoneit, B. R. T.: Measurement of emissions from air pollution sources. 3. C1-C29 organic compounds from fireplace combustion of wood, Environ. Sci. Technol., 35, 1716-1728, 2001.

Schkolnik, G., Falkovich, A. H., Rudich, Y., Maenhaut, W., and Artaxo, P.: New analytical method for the determination of levoglucosan, polyhydroxy compounds, and 2-methylerythritol and its application to smoke and rainwater samples, Environ. Sci. Technol., 39(8), 2744-2752, 2005.

Schkolnik, G. and Rudich, Y.: Detection and quantification of levoglucosan in atmospheric aerosols: A review, Anal. Bioanal. Chem., 385(1), 26-33, 2006.

Schmidl, C., Bauer, H., Dattler, A., Hitzenberger, R., Weissenboeck, G., Marr, I. L., and Puxbaum, H.: Chemical characterisation of particle emissions from burning leaves, Atmos. Environ., 42, 9070-9079, 2008.

Schmidl, C., Marr, I. L., Caseiro, A., Kotianova, P., Berner, A., Bauer, H., Kasper-Giebl, A., and Puxbaum, H.: Chemical characterization of fine particle emissions from wood stove combustion of common woods growing in mid-European Alpine regions, Atmos. Environ., 42, 126-141, 2009.
Shafidazeh, F.: The chemistry of pyrolysis and combustion, Adv. Chem. Ser., 207, 489-529, 1984.

Sheesley, R. J., Schauer, J. J., Chowdhury, Z., Cass, G. R., and Simoneit, B. R. T.: Characterization of organic aerosols emitted from the combustion of biomass indigenous to South Asia, J. Geophys. Res., 108(D9), 4285, doi:10.1029/2002JD002981, 2003.

Simoneit, B.: A review of biomarker compounds as source indicators and tracers for air pollution, Environ. Sci. Pollut. Res., 6, 159-169, 1999a.

Simoneit, B., Schauer, J., Nolte, C., Oros, D., Elias, V., Fraser, M., Rogge, W., and Cass, G.: Levoglucosan, a tracer for cellulose in biomass burning and atmospheric particles, Atmos. Environ., 33 , 173-182, 1999b.

Simoneit, B. and Elias, V.: Detecting organic tracers from biomass burning in the atmosphere, Mar. Pollut. Bull., 42, 805-810, 2001.

Simpson, C. D., Dills, R. L., Katz, B. S., and Kalman, D. A.: Determination of levoglucosan in atmospheric fine particulate matter, J. Air Waste Manage. Assoc., 54, 689-694, 2004.

Wan, E. C. H. and Yu, J. Z.: Analysis of sugars and sugar polyols in atmospheric aerosols by chloride attachment in liquid chromatography /negative ion electrospray mass spectrometry, Environ. Sci. Technol., 41, 2459-2466, 2007.

Welthagen, W., Schnelle-Kreis, J., and Zimmermann, R.: Search criteria and rules for comprehensive two-dimensional gas chromatography-time-of-flight mass spectrometry analysis of airborne particulate matter, J. Chromatogr. A, 1019(1-2), 233249, 2003.

Williams, B., Goldstein, A., Kreisberg, N., and Herring, S.: An in-situ instrument for speciated organic composition of atmospheric aerosols: Thermal Desorption Aerosol GC/MS-FID (TAG), Aerosol Sci. Technol., 40, 627-638, 2006.

Yttri, K. E., Dye, C., Slordal, L. H., and Braathen, O.-A.: Quantification of monosaccharide anhydrides by liquid chromatography combined with mass spectrometry: Application to aerosol samples from an urban and a suburban site influenced by small-scale wood burning, J. Air Waste Manage. Assoc., 55, 1169-1177, 2005.

Zdrahal, Z., Oliveira, J., Vermeylen, R., Claeys, M., and Maenhaut, W.: Improved method for quantifying levoglucosan and related monosaccharide anhydrides in atmospheric aerosols and application to samples from urban and tropical locations, Environ. Sci. Technol., 36, 747-753, 2002.

Zheng, M., Cass, G. R., Schauer, J. J., and Edgerton, E. S.: Source apportionment of $\mathrm{PM}_{2.5}$ in the southeastern United States using solvent-extractable organic compounds as tracers, Environ. Sci. Technol., 36, 2361-2371, 2002. 